\title{
A Case for mirativity and mirative markers in Kashmiri
}

\author{
Musavir Ahmed
}

\section{DOI: 10.18355/XL.2017.10.03.13}

\begin{abstract}
The paper discusses the mirative use of a marker in Kashmiri that hasn't been reported in grammars and linguistic works of the language. The use of this marker /hee/ with variants of /hai/ and /haa/, within declarative or negative sentences by a speaker conveys surprise or counterexpectation reflecting his or her sudden discovery or realization of something or an unprepared mind or disapproval. The marker is equally used by a speaker to generate surprise in his or her addressee. The marker usually follows the subject noun or pronoun as a kind bound affix in a sentence. Use of two variants of the marker in a single sentence, with one following the subject noun or pronoun and the other placed between auxiliary and main verb is also common in the language. A third marker /nai/ can also be found in affirmative and negative sentences with a regular negative marker with more or less similar functions as that of /hee/. However the three variants /hee - hai - haa/ have exclamatory functions also, when used independently or in combination with each other. The paper is a preliminary study highlighting the mirative use of these markers in various contexts.

Key words: Kashmiri, mirativity, exclamation, honorification, Dardic
\end{abstract}

\section{Introduction}

In the recognition of Mirativity as an independent grammatical category, the work of DeLancey (1997) is often considered a milestone. Building on previous studies like Slobin and Aksu (1983), Egerod and Hansson (1974), Aronson (1967), Friedman (1986) and others, and his own understanding of Tibetian and Hare languages, DeLancey $(1997,2001)$ raised mirativity from a sub-category of evidentiality to an independent category thereby defining it as a category which "marks both statements based on inference and statements based on direct experience for which the speaker had no psychological preparation, and in some languages hearsay data as well" (1997: 35). The information presented by such statements or propositions which are marked for mirativity is new and not yet part of the speaker's knowledge structure.

Reporting on the use of sentence final particle lo in Hare, DeLancey (1997) observes that the particle is used by a speaker of the language to mark his or her physical observation or "direct observation" of whatever is being reported. The information which the speaker is reporting is "unanticipated" and without any previous knowledge of it and thus has overtones of surprise $(39-40)$. And as such what is being marked through the particle is "not the fact itself" but rather "the speaker's discovery of the fact" (40).

According to Hyslop (2011), over the last two decades, mirativity has been reported to be present in dozens of languages from various language families. The author also separates mirativity from evidentiality and epistemic modality. While evidentiality reflects "the source of knowledge" and epistemic modality reveals the "certainty of knowledge", mirativity is "concerned with the expectations of knowledge" (43).

Aikhenvald (2012) while presenting a comprehensive typological account of the mirative meanings and markers in the languages of the world has subsumed a series of related meanings under the label mirative. These include sudden discovery, revelation or realization, surprise, unprepared mind, counterexpectation and new information and the realization of these meanings takes place with reference to the speaker, hearer 
or to the main character (437). The work has presented several examples from a wide range of languages to substantiate the above definition. These include instances where mirativity is expressed though "complex verbal constructions", "special verbal affix or particle" or "special series of pronouns" in different languages (438).

Among the languages that use special verbal constructions to express mirativity, the work cites the example of two Tibeto-Burman languages Magar and Kham, northeast Caucasian languages of Archi and Tsakhur and Tariana, an Arawik language from northwest Amazonia. Languages in which mirative meanings are expressed through verbal affixes as exemplified by the work are Chechen, !Xun a north Khoisan language, Caddo, a Caddoan language of North America, a dialect of nDrapa that belongs to the Qinagic subgroup of Tibeto-Burman and several Quechuan languages spoken in Andes. Mirative meanings expressed through pronouns have been reported in Shilluk, a Western Nilotic lanaguge and Hone, a Jukanoid language from BenueCongo Family. Independent means of expressing mirativity mentioned by the work include use of a clitic in Lillooet and "emphatic marker" in Musqueam, two Salish languages, "nominalization of a stative verb" or a "clitic homophonous with an interrogative marker" in Haida, a language isolate, "exclamative tense" in Wichita, a Coddoan language and an "apperceptive" marker in Korean (446-458).

While further building a case for independent status of mirativity to corroborate Delancey's (2001) conclusion, Aikhenvald (ibid) observes that "expression of evidential is completely independent of the mirative markers" and in most of the languages reported in the work "evidentials do not have mirative extensions" (457).

A lucid account of mirativity as a widespread phenomenon has been presented in Bashir (2006). The work has typologized the means of expressing mirativity in a number of South Asian languages including modern IndoAryan languages and Dravidian languages. For example in Khowar, the author reports the use of huLa (past participle form of the verb hik 'to become') to express mirative meaning. The use of huLa, besides reflecting that the speaker just learned about the activity being reported, is also used to express surprise, regret or annoyance. In Nepali, the mirativity is expressed by a specific copula rahecha which is reflective of the speaker's unawareness of a situation being reported. According to the study, languages in which verbal system is involved in the expression of mirativity include Kalasha, Khowar, Yasin Burushaski, Wakhi, Tajik Persian and the three Nuristani languages of Ashkun, Kamviri and Waigali. Dedicated particles for expression of mirativity are found in languages like Hunza Burushaski, Pashto and Malayalam. Other languages having specific verbs for mirativity include Tamil, Telugu, Kannada and Dakkhini Urdu. According to Kaushal (1979) Ladakhi also has a mirative particle tshuk (reported in Bashir, 2010). The author has also reported a special use of the stem bil of past form of verb boonu to become in several dialects of Shina, however no dedicated mirativity marker has been found in Shina (Bashir 2010).

\section{Kashmiri}

Kashmiri is a language of more than seven million people primarily concentrated in northern most state of Jammu and Kashmir (J\&K) in India. Some Kashmiri speakers can be found in the part of Kashmir administered by Pakistan (PAK). Kashmiri along with several other languages of the northern areas were classified by Grierson (1919) under a separate branch of Indo-Iranian called Dardic.

According to Grierson (1919: 2), Dardic as a separate branch of Indo-Iranian, comprises of three groups:

The Kafir group

The Khowar group

The Dard group proper

The Dard group proper includes Shina, Kashmiri and Kohistani. 
However, the linguistic basis of Grierson's classification of Dardic languages has been challenged following the works of Georg Morgenstierne (1926, 1932, 1961). In the first instance, Morgenstierne (1926) dissociated the languages of Kafir group from Dardic family of languages. Subsequent works of Morgenstierne were able to establish that the languages classified by Grierson as Dardic, except thereof Kafir group, are in fact Indo-Aryan languages.

"there is not a single common feature distinguishing Dardic, as a whole, from the rest of the IA languages....... Dardic is simply a convenient term to denote a bundle of aberrant IA hill languages, which in their relative isolation have been in a varying degree sheltered against the expanding influence of IA midland (Madhyadesha) innovations being left free to develop on their own" (Morgenstierne, 1961: 139, cited in Peterson, 2006: 22).

Grierson's use of the term Dardic as an umbrella term for the languages spoken in the mountainous belt spanning from Kashmir to northern Afghanistan has been attributed to Leitner's $(1880,1893)$ use of the term Dardistan.

Leitner's Dardistan, in its broadest sense, became the basis for the classification of the languages in the north-west of Indo-Aryan (IA) linguistic area (which includes the present day Afghanistan, northern Pakistan and Kashmir) (Mock, 1997).

Subsequent linguistic works, some of them based on extensive field work in the area further substantiated Morgenstierne's viewpoint. Prominent among these works are Fussman (1972), Strand (1973), Masica (1991), Radloff (1992), Bashir (2003), Zoller (2005), Schmidt and Kohistani (2008) and Liljegren (2008).

According to Bashir 'the designation 'Dardic' neither implies ethnic unity among the speakers of these languages nor that they can all be traced to a single Stammbaummodel node".

Earlier Strand (2001:251), following in the footsteps of Morgenstierne, had gone one step further in suggesting that the term 'Dardic' should be abandoned from usage in favor of more appropriate name Northwest Indo Aryan languages.

"Dardic is a geographical cover term for those Northwest Indo-Aryan languages which because of their isolation in the mountains of Hindu Kush, Swat and Indus Kohistan, the Karakorams and Western Himalayas have retained ancient and developed new characteristics different from the IA languages of the Indo-Gangetic Plain. (Bashir, 2003:821-822)

As far the uniformity among these languages is concerned, She notes that these "languages on the whole underwent fewer of the major MIA phonological and morphological developments than plains IA" (ibid.).

Radloff refers to the languages "clustered in the mountainous areas of northern Pakistan and stretch into Kashmir on the east and Afghanistan on the west" as Dardic (Radloff, 1999:4).

Zoller also makes use of the term Dardic and believes that these languages are "the modern successors of Middle Indo-Aryan (MIA), Gandhari and other unknown MIA languages" (Zoller 2005:10). He upholds that the Dardic languages developed from "Proto-Dardic" that branched off "at a post OIA stage from the rest of the Indic" (ibid.).

Bashir (2003:824-825) has proposed a detailed classification of the Dardic languages. According to her, the major groups given as under have been arranged from West to East.

I. Pashai

II. Kunar

III. Chitral

IV. Kohistani

V. Shina

XLinguae Journal, Volume 10 Issue 3, June 2017, ISSN 1337-8384 
VI. Kashmiri

\section{Mirativity and Mirative Markers in Kashmiri}

To begin with, consider a situation where two individuals A and B, say two colleagues or two members of a family are in knowledge of some job which A has to perform. While A is at the job, B doesn't expect the job to be completed soon. When B suddenly finds that A has completed the job by his own eyes, he may address A in the following two ways:

(1) tse chuth muakluawmut

You $\operatorname{Erg}^{1}$ be complete Perf

you have completed

tse hee chuth muakluawmut

You Erg MM be Complete Perf

you have completed

In both the cases, the communicative value of the statements is zero for $\mathrm{A}$, as he/she already knows that he/she has completed the job. So what is being communicated is B's discovery of the fact that A has really completed the job. While both the statements reflect B's own awareness of the completed job, the marker/-hee/ in (2), adds B's surprise to the statement, which (1) lacks. The marker/-hee/ has a clear rising tone, but overall the intonation pattern of both the statements is similar in their normal declension.

In sentence (2), the speaker's surprise has the overtone of happiness because the job has been done which was not expected of the addressee at least at the time, the speaker visually observed it. In a situation, where the speaker finds that his share of food is eaten by the addressee, he has the following options:

$$
\begin{aligned}
& \text { tse chuth suarlj muakluawmut you have finished everything } \\
& \text { You Erg be everything finish Perf } \\
& \text { tse hee chuth suarlj muakluakwmut you have finished everything } \\
& \text { You Erg MM be everything finish Perf }
\end{aligned}
$$

In (4), the speaker expresses his surprise when observing that his share of food has been eaten too, but here it has the overtone of displeasure or disapproval.

In a similar situation as depicted in (1) and (2), if B finds that A hasn't completed much of the job which he had expected, B can express his sudden discovery that the job hasn't progressed much in following two ways:

tse chuth ni kinhi kormut

You Erg be Neg nothing do Perf

tse hee chuth ni kinhi kormut

You Erg MM be Neg nothing do Perf

you haven't done anything

you haven't done anything!

Again in (6), the marker /hee/ adds B's own surprise to the expression of his own discovery that not much has been done by A. The marker /hee/ here has rising intonation like in (2). The marker /hee/ is neutral with regard to the gender of the speaker and addressee.

1 Erg - Ergative, Nom - Nominative, Perf - Perfect, Impf - Imperfect, Fut - Future, Neg - Negative, MM - Mirative Marker 
In a situation as depicted in (3) and (4), if the speaker finds that the addressee hasn't eaten much against his/her expectations, the speaker say the following options:

$$
\begin{aligned}
& \text { tse chuth ni kinhi khjomut you haven’t eaten anything } \\
& \text { You Erg be Neg nothing eat Perf }
\end{aligned}
$$

$$
\text { tse hee chuth ni kinhi khjomut you haven’t eaten anything! }
$$

You Erg MM be Neg nothing eat Perf

In (7) and (8) the addressee already knows that he/she hasn't eaten much but the marker /hee/ in reflects the speaker's surprise.

A perfect example of the particle /hai/ in Kashmiri would be when a speaker expresses his surprise upon seeing the addressee whom he/she hadn't expected at a certain time or place in the following way:

$$
\begin{aligned}
& \text { tsi hai aakh } \\
& \text { You Nom MM come Perf }
\end{aligned}
$$

you came

If the addressee is a female then the expression would be as below:

(10) tsi hai aayekh
You MM come Perf Fem

In both (9) and (10), the addressee doesn't need to know that he or she has come and the speaker is actually expressing his or her own counterexpectation and surprise when he suddenly sees the addressee. In these situations, use of statements (9) and (10) without the marker /hai/ has less acceptability if not totally inappropriate unlike what was with (1) and (2) or (3) and (4).

The mirative marker in Kashmiri however is not restricted to second person only; it can be found to be frequently used in first and third person. Kashmiri has a two-way system in third person, one for third person proximate (within the range of sight) and another for third person remote (out of sight).

Consider a situation where a person is visiting his friend after a long time and looking at his friend's child who has grown up since the time he has seen him last, the person can use the following:

$$
\begin{aligned}
& \text { tsi chukh boD gomut } \\
& \text { You Nom be big go Perf } \\
& \text { tsi hai chukh boD gomut } \\
& \text { You be big go Perf }
\end{aligned}
$$

you have grown up

you have grown up

And while addressing his friend, the child's father or his mother, the person again has a choice between a statement with mirative marker or without it as in following:

$$
\begin{aligned}
& \text { yi chu boD gomut } \\
& \text { He Nom be big go Perf } \\
& \text { yi hee chu boD gomut } \\
& \text { He Nom MM be big Perf }
\end{aligned}
$$$$
\text { he has grown up }
$$

he has grown up

While narrating his visit to his friend's place, the person at his own home referring to his friend's son has again the choice between the following: 
If the addressee in (16) is a female then /hai/ is used. Both (15) and (16) convey new information to the addressees (here the person's own family members) that his friend's child has grown up and as such have a certain communicative value, like a normal declarative sentence. In (16) the person uses the mirative marker /haa/ to create surprise among addressees by actually expressing his own surprise. In response, the family members can say a prayer or blessing to the person's friend's son.

The use of mirative marker in (2), (4), (6), (8), (10), (12), (14) and (16) express the speaker's surprise on the basis of his/her sudden observation or realization which is direct i.e. where the speaker's own sense of vision is involved. The mirative marker in Kashmiri is also used to create an expectation or hope or assurance for an addressee by a speaker about some future event. Here the speaker by drawing on his or her own inference actually wants to reassure the addressee about the completion of some future event or job.

Consider a situation where for example, some guests are visiting a household in the evening and the food to be served to them seem to take much time in cooking or is in process of cooking. When asked about his or her preparedness expressive of a kind of worry, the person in charge of cooking may respond in the following manner:

$$
\begin{aligned}
& \text { bI muakilaawi tiitis kaalas I will complete by that time } \\
& \text { I Nom complete Impf by that time } \\
& \text { bI haa muaklwaawi tiitis kaalas I will complete by that time } \\
& \text { I Nom MM complete Impf by that time }
\end{aligned}
$$

The marker /haa/ in (18) expresses a kind of reassurance to the addressee that the food will be ready by the time the guests arrive. In this situation, the speaker is drawing on his inference to convey the reassurance. If the enquirer is of feminine gender, the marker used will take the form /hai/. In a similar situation if the enquirer somehow feels that the person responsible for cooking isn't certain about the preparation, he or she may encourage the cooking in-charge through the following:

$$
\begin{aligned}
& \text { ma baambar tsi muaklaawakh tiitis kaalas } \\
& \text { don't worry you Nom complete Impf by that time }
\end{aligned}
$$

ma baambar tsi haa muaklaawakh tiitis kaalas Don't worry you Nom MM complete Impf by that don't worry you will complete by that time

don't worry you will complete by that time

In (20), the mirative marker /haa/ is used to convey assurance to or encouragement for the person who in charge of cooking that the food will be ready by the time the guests arrive.

The marker /hai - haa/ is used in negative sentences as well. Consider a person who is being asked to do something but he or she isn't willing to do it. The person has the following options available: 
bI karI nI

I Nom do Impf Neg

bI haa karI ni

I Nom MM do Impf Neg

bI naa karI nI

I Nom MM do Impf Neg
I won't do

I won't do

I won't do

Of the above three statements, (21) is the neutral or unmarked way of refusing to do something. In (22), the affix /haa/ reflects a kind of desperation or helplessness on the part of the speaker, which may simultaneously surprise the addressee. It is a sort of last moment 'no' by the speaker to something, of which the addressee was sure and is thus surprised to hear it. In (23), the /naa/ seems to be a negative marker, but since the sentence has the regular negative marker /nI/ like in (21) and (22) so it may have some other function which I believe is that of communicating a sort of desperation of helplessness on the part of speaker. It may have a mirative function in the sense that the answer may surprise the addressee. I believe it functions as a negative mirative marker in sentences wherein a regular negative marker is also present. Sentences (22) and (23) have same effect on the addressee and both /haa/ and /naa/ in several contexts are sensitive to the gender of the addressee; these become /hai/ and /nai/ if the addressee is a female as below:
bI hai karI ni
I won't do
I Nom MM do Impf Neg
bI nai karI nI
I won't do
I Nom MM do Impf Neg

The marker /naa - nai/ is also used in affirmative sentences either independently or along with /haa/. In such sentences, /nai/ is used with both male and female addressee having third person singular subjects. In affirmative sentences /naa - nai/ has similar function as that of mirative marker /haa - hee - hai/ and as such I believe these are also mirative markers. Consider a situation which reports the completion of a job (by a third person) to an addressee. The speaker has the following options:
tem kor
he did
He Erg do Perf

tem haa kor

he did

He Erg MM do Perf

tem haa kor nai he did

He Erg MM do Perf MM

tem kor nai he did

He Erg do Perf MM

While all the above four sentences have same communicative value for the addressee, (26) is unmarked in comparison to other three. In (27) the marker /haa/ is employed as a kind of added assurance and satisfaction that the work has been done. There is also an element of surprise in (27), but expression of assurance and satisfaction is

XLinguae Journal, Volume 10 Issue 3, June 2017, ISSN 1337-8384 
dominant. Sentences (28) and (29) have more or less the same effect as (27). If the speaker is referring to his/her own self the marker /nai/ becomes /mai/ as below:
me haa kor mai
I did
He Erg MM do Perf MM
me kor mai
I did
He Erg do Perf MM

Often the sentences (27) to (29) are used by Kashmiri speakers in a satirical way, when it reports either a bad job or a loss at job as below:
tem haa kor kaar
He Erg MM do Perf MM
he did the job
tem haa kor nai kaar
He Erg MM do Perf MM
he did the job
tem kor nai kaar
He Erg MM do Perf MM
he did the job

In the above sentences /haa/ and/or /haa - nai/ conveys surprise over the bad job or loss and disapproval of the person responsible for it.

Sentences (26) to (29) can be negativized with a similar kind of effect. Often the sentences go with the word/kinhii/ 'nothing' following the negative marker as below:

$$
\begin{array}{ll}
\text { tem kor nI kinhii } & \text { he didn't do anything } \\
\text { He Erg do Perf Neg Nothing } & \\
\text { tem haa kor nI kinhii } & \text { he didn't do anything } \\
\text { He Erg MM do Perf Neg Nothing } &
\end{array}
$$

$$
\begin{aligned}
& \text { tem haa kor nai nI kinhii } \quad \text { he didn't do anything } \\
& \text { He Erg MM do Perf MM Neg Nothing }
\end{aligned}
$$

$$
\begin{aligned}
& \text { tem kor nai nI kinhii } \quad \text { he didn't do anything } \\
& \text { He Erg do Perf MM Neg Nothing }
\end{aligned}
$$

The sentences (30) and (31) can also be negativized with the regular negative marker $/ \mathrm{nI} /$ but with /mai/ as it is in affirmative sentences:

$$
\begin{aligned}
& \text { me haa kor mai nI } \quad \text { I didn’t } \\
& \text { He Erg MM do Perf MM }
\end{aligned}
$$

$$
\begin{aligned}
& \text { me kor mai nI } \\
& \text { He Erg do Perf MM }
\end{aligned}
$$

I didn't

In Kashmiri, linguistic modes of honorification are common and several such markers can be found in the language. Some of the markers are /hez/, /hasa/, /sa/ and /haw/; /hez/, /hasa/ and /sa/ are gender neutral while as /haw/ is specific to female addressees among Kashmiri speakers of Srinagar, the capital city of Kashmir.

Use of marker /haa/ in all the sentences discussed so far is informal and interestingly it's the mirative marker /haa/ which gets converted into /hez/, /hasa/, /sa/ and /haw/ to show respect to the addressee. Most of the sentences reported so far can have the 
honorific markers in place of the mirative marker /haa/. Consider the following examples:

tse hez chuth muakluawmut You Erg HM (MM) be Complete Per

tsi hez aayekh

You Nom HM (MM) come Perf Fem

time

bi hez muaklaawi tiitis kaalas

I HM (MM) complete Impf by that time

tem hez kor

He Erg HM (MM) do Perf

you have completed

you came

I will complete by that

In (41) /tse/ second person pronominal (Ergative) is frequently replaced with /tuahi/ the honorific counterpart, to agree with the marker /hez/. In (42)/tsi/ is replaced with /tuhj/, the honorific counterpart of second person (Nominative) and the verb /aajekh/ is replaced with its honorific form /aajiw/ to agree with the marker/hez/ as below:

$$
\begin{aligned}
& \text { tuhj hez aajiw } \\
& \text { You Nom HM (MM) come Perf }
\end{aligned}
$$

you came

The marker /hez/ in the works on Kashmiri language has been exclusively treated as honorific marker and rightly so, but these can simultaneously reflect mirative meanings of surprise or counterexpectation like /hee - hai/. The use of /hez/ in comparison to /hee - hai/ indicates that the relationship between an addressee and addresser is formal one or the addressee is elder to addresser or the relationship by means of a social rule demands the use of a honorif marker by the speaker, however the element of surprise or counterexpectation is very much there even if it seems to be dormant as against in the use of /hee-hai/ where it is more pronounced.

In sentence (41) the speaker expresses surprise through /hez/ when he/she finds that the work has been done besides showing honour to the addressee, while as in (42) and (45), /hez/ reflects the counterexpectation of the speaker, when he/she finds that the addressee turns out at a place/time where she wasn't expected besides honouring her. In sentence (43), the speaker by using /hez/ communicates extra assurance to the addressee that the job will be done, besides displaying the honour. Similarly /hez/ in (44) besides being an honorific marker also communicates the surprise and counterexpectation of the speaker which may be surprising to the addressee as well.

In a situation where a speaker and an addressee seemingly meet for the first time, but the speaker upon seeing the addressee realises that he/she knows him before, he/she may have following options:

bi zaanath tsi

I know you

I Nom know Perf you

bi haa zaanath tsi

I know you

I Nom know Perf you

bi hez zaanath tsi

I know you

I Nom know Perf you

XLinguae Journal, Volume 10 Issue 3, June 2017, ISSN 1337-8384

171 
Sentence (46) is unmarked and informal one while as (47) is informal but marked for mirativity and communicates the counterexpectation of the speaker and may simultaneously create surprise in the addressee as well. If the situation is formal and demands the use of honorification, a speaker may use (48) or (49), with (49) being expressive of highest honour to the addressee.

The negative mirative marker /naa - nai/ as discussed in sentences (21) to (29) also go with the honorific marker/hez/. In sentences with the honorific marker/hez/ the function of /naa - nai/ is same as that in sentences with the mirative marker /haa - hee - hai/. Consider the following:

$$
\begin{aligned}
& \text { tem hez kor nai } \\
& \text { He Erg HM (MM) do Perf MM }
\end{aligned}
$$

he did

On the analogy of (30), if the speaker refers to himself, the marker /nai/ takes the form /mai/ as below:

$$
\begin{aligned}
& \text { me hez kor mai } \\
& \text { I Erg HM (MM) do Perf MM }
\end{aligned}
$$

I did

Sentences (50) and (51) can be negativized with the use of regular negative marker $/ \mathrm{nI} /$ in Kashmiri as below:

$$
\begin{array}{ll}
\text { tem hez kor nai nI } & \text { he didn’t } \\
\text { He Erg HM (MM) do Perf MM Neg } & \\
\text { me hez kor mai nI } & \text { I didn't } \\
\text { I Erg HM (MM) do Perf Neg } &
\end{array}
$$

In sentences (50) and (51), the marker /nai - mai/ like in earlier examples serve to express a kind of satisfaction coupled with a bit of surprise that may create surprise among the addressee as well, while as in (52) and (53), the marker may convey a disapproval or desperation as well as surprise by the speaker which may be surprising for the addressee also.

The markers /hee - haa - hai/ are frequently used by speakers of Kashmiri as exclamatory markers to express mild grief or sadness and are placed at the beginning of sentences in following ways:

$$
\begin{aligned}
& \text { hai/ hai hai me aaw khuun } \\
& \text { Oh I Erg come Perf blood }
\end{aligned}
$$

Oh I bled

hai hee ji phuTrouwuth Alas this broke Perf

haaj ji kyah koruth Oh this what do Perf

hee kyah wanaj panIn sitam Oh what tell Fut mine misfortunes
Alas you broke it

Oh what did you do?

Oh what shall I tell you about my misfortunes 


\section{Conclusion}

Kashmiri has neither been reported for the presence of evidentiality or mirativity. The study reported a preliminary inquiry into the presence of mirativity and mirative markers in the language. Such markers like /hee/, /hai/ and /haa/ within a sentence are used to express surprise, counterexpecation, assurance, disapproval, satisfaction etc by a speaker who suddenly realises, by his sense of vision or by inference anything being reported. The use of these markers in many contexts also creates surprise or disapproval among the addressee, besides the speaker. Sentences (1), (4), (6) and (8) demonstrated the use of /hee/ by a speaker to express surprise, counterexpectation and unprepared mind by visually observing the activity being reported. In case of (1), the surprise of the speaker accompanies his/her happiness and satisfaction while as in (4), (6) and (8) surprise is accompanied by the disapproval on the part of the speaker. In all these cases, the communicative value of the sentences is zero for the addressee as he/she already knows what is being said of the activity. So the actual semantic value of these sentences lies in the surprise element these convey. Similarly the sentences (9), (10), (12), (13), (14) and (16) actually convey surprise and counterexpecation of the speakers more than anything else when they actually observe the act being reported by their own eyes. In (18) and (20) the marker /haa/ has slightly different function where it serves to express the reassurance of the speaker for the addressee. In these two sentences the speakers rely on their inferences. Sentences (21) to (25) report the use of the markers /haa - hai / in negative sentences. In (22), the marker /haa/ conveys a kind of desperation by the speaker which may be surprising for the addressee. The markers /naa - nai/ in (23) and (25) which are seemingly negative markers in Kashmiri, however seem to attain different function in presence of regular negative marker within the same sentence. This function is that of conveying desperation or inability to do something on the part of the speaker which may at the same time be surprising to the hearer. The simultaneous use of /haa/ and /nai/ within a single affirmative sentence is quite challenging to explain. Since the markers /naa nai/ seem to be negative markers and their role may be somehow understood in negative sentences, but their presence in affirmative sentences is puzzling. What I believe is that use of /naa - nai/ within a negative sentence having a regular negative marker is that of furthering the intensity of negation or reflecting the desperation or compulsion of the speaker in not doing an act being reported which may surprise the addressee. And their presence in affirmative sentences with or without the marker /haa - hai/ is to convey satisfaction or happiness coupled with a low intensity of surprise which may create satisfaction and surprise in the hearer. In sentences (41) to (45) where the speaker is bound to display respect or formality, the honorific or formal marker /hez/ is used in place of the mirative marker /haa/. However I believe that this doesn't take away the surprise value of the sentences which is simultaneously carried by /hez/ besides being a marker for respect. The communicative value of sentences (46), (47) and (48) is zero for the addresses and a comparison between the three further elaborates the idea that as against (46) which is unmarked for honorification and mirativity, the presence of /haa/ in (47) and /hez/ in (48) equally convey surprise of the speaker when he/she sees the addressee physically and may also invoke latter's surprise. In addition /hez/ in (48) is used by the speaker to show respect or formality to the addressee.

The understanding of mirativity and the mirative markers presented here is by no means final and may need further insights, given nothing of this kind has been reported before. This may also be for the fact that in depth works on mirativity have begun to emerge only recently. Being a native speaker of Kashmiri, I believe the 
grammatical/ semantic potential of the markers /haa - hee - hai/ have not been fully explored and require fresh attention of the linguistic scholars.

\section{Bibliographic references}

AIKHENVALD, ALEXANDRA Y. 2003. Evidentiality in Tariana. In: Alexandra Y. Aikhenvald \& Robert M. W. Dixon. Eds.. Studies in Evidentiality. Amsterdam: Benjamins. ISBN 9789027229625

AIKHENVALD, ALEXANDRA Y. 2004. Evidentiality. Oxford: Oxford University Press. ISBN 0199204330

AIKHENVALD, ALEXANDRA Y. 2007. Information source and evidentiality: What can we conclude? Rivista di Linguistica 19: 207-227. ISSN 1120-2726

Aikhenvald, Alexandra Y. 2012. The essence of mirativity. Linguistic Typology 16: 435-485. ISSN 1613-415X

AKSU-KOÇ, AYHAN A. - SLOBIN, D. I. 1986. A psychological account of the development and use of evidentials in Turkish. In: Wallace L. Chafe \& Johanna Nichols. Eds.. Evidentiality: the Linguistic Coding of Epistemology. Norwood, N.J.: Ablex. ISBN 0893912034

BASHIR, ELENA. 1988. Inferentiality in Kalasha and Khowar. Proceedings of the 24th Regional Meeting of Chicago Linguistic Society. Chicago: Chacigo Linguistic Society, 47-59. ISBN 0914203274

BASHIR, E. 2006. Evidentiality in South Asian Languages. In: Miraim Butt \& Tracy Holloway King. Eds.. Proceedings of the LFG06 Conference, Workshop on South Asian Languages Konstanz Universitat. Standford:CSLI Publications ISSN 10986782

BASHIR, E. 2010. Traces of Mirativity in Shina. Himalayan Linguistics 9 (2): 1-55. ISSN:1544-7503

http://www.linguistics.ucsb.edu/HimalayanLinguistics/articles/2010/PDF/HLJ0902A. pdf

DELANCEY, SCOTT. 1986. Evidentiality and volitionality in Tibetan. In: Wallace L. Chafe \& Johanna Nichols. Eds.. Evidentiality: the Linguistic Coding of Epistemology. Norwood, N.J.: Ablex. ISBN 0893912034

DELANCEY, SCOTT. 1990. A note on evidentiality in Hare. International Journal of American Linguistics 56:152-158. ISSN 0020-7071

DELANCEY, SCOTT. 1997. Mirativity: The grammatical marking of unexpected information. Linguistic Typology 1: 33-52. ISSN 1613-415X

DELANCEY, SCOTT. 2001. The mirative and evidentiality. Journal of Pragmatics 33: 369-382. ISSN 0378-2166

DELANCEY, SCOTT. 2003. Lhasa Tibetan. In: Graham Thurgood \& Randy J. LaPolla. Eds.. The Sino- Tibetan Languages. London: Routledge. ISBN 1138783323

GRIERSON, G. A.1919. The Linguistic Survey of India, VIII (II). Delhi: Motilal Banarsidas. http://www.new.dli.ernet.in/handle/2015/175662. ISBN N/A

KACHROO, B. B. 1969. A Reference Grammar of Kashmiri. Urbana: Department of Linguistics, University of Urbana. ISBN N/A

KOSHAL, SANYUKTA. 1979. Ladakhi Grammar. Delhi: Motilal Banaraidass. ISBN N/A

KOUL, O. N. 1977. Linguistic Studies in Kashmiri. Delhi: Bahri Publications. ISBN N/A

KOUL, O. N - WALI, KASHI. 2006. Modern Kashmiri Grammar. Springfiled: Dunwoody Press. ISBN: 1-931546-07-X

MASICA, C. P. 1991. The Indo-Aryan Languages. Cambridge: Cambridge University Press. ISBN 0521234204

RAZDAN, S. 2000. Kashmiri Grammar: History and Structure. Srinagar: Vijay Deep Publications. ISBN N/A 
SCHMIDT, R. L. - KOHISTANI, R. 2008. A Grammar of the Shina Language of Indus Kohistan. Wiesbaden: Harrassowitz Verlag. ISBN 9783447056762

SLOBIN, DAN I. - AKSU-KOÇ, AYHAN A.. 1982. Tense, aspect, and modality in the use of the Turkish evidential. In: Paul J. Hopper. Ed.. Tense-Aspect: Between Semantics and Pragmatics. Amsterdam: Benjamins. ISBN 9789027228659

Words: 5814

Characters: 35014 (19,45 standard page)

Dr. Musavir Ahmed, Senior Assistant Professor

Department of Linguistics,

University of Kashmir,

Srinagar,

J\&K, India 190006

musavir@uok.ed.in 